American Journal of Environmental Sciences 4 (6): 716-720, 2008

ISSN 1553-345X

(C) 2008 Science Publications

\title{
Bentonite used as Adsorbent Agent of the Coupling Adsorption Ultrafiltration of the Secondary Effluents for their Reuse
}

\author{
D. Abdessemed and G. Nezzal \\ Laboratory of Processes Engineering- Environment, \\ University of Sciences and Technologies Houari Boumedie ne, \\ B.P. 32 El Alia 16111, Bab Ezzouar, Algiers, Algeria
}

\begin{abstract}
This present study has for principal objective to treat secondary effluents of the Staoueli purification plant (Algeria) with the average characteristics in the Chemical Oxygen Demand (COD) is $76 \mathrm{mg} \mathrm{L}^{-1}$ and $16 \mathrm{NTU}$ of turbidity by adsorption ultrafiltration coupling for its reuse in irrigation or in industry to reduce the water demand. A mineral ultrafiltration tubular membrane of CARBOSEP M2 $\left(15 \mathrm{Kg} \mathrm{mo}^{-1}\right)$ in dynamic mode with a transmembrane pressure $\Delta \mathrm{P}=1$ bar and a cross flow velocity $\mathrm{U}=3 \mathrm{~m} \mathrm{sec}^{-1}$ was used for this purpose. The adsorbent choice was made on an Algerian bleaching ground: the bentonite available on the market with low cost. It has sorptives properties and ions exchange with specific area $250 \mathrm{~m}^{2} \mathrm{~g}^{-1}$. In the first step, we considered the organic matter adsorption on bentonite in static mode (jar test). The optimal conditions were determined corresponding to the best elimination of the Chemical Oxygen Demand with a final value equal to $30.6 \mathrm{mg} \mathrm{\textrm {L } ^ { - 1 }}$ and turbidity, in jar test with $1.5 \mathrm{NTU}$ value for an optimal bentonite concentration equal to $10 \mathrm{~g} \mathrm{~L}^{-1}$. In the second step, the adsorption ultrafiltration coupling, showed a final value in COD equal to $9.2 \mathrm{mg} \mathrm{L}^{-1}$ and final turbidity equal to 1.2 NTU. An improvement of the permeate flux was showed equal to $48.8 \%$ for the optimal concentration bentonite $10 \mathrm{~g} \mathrm{~L}^{-1}$. The adsorption significantly improves the ultrafiltration performances.
\end{abstract}

Key words : Bentonite, ultrafiltration, secondary effluents, adsorption, reuse

\section{INTRODUCTION}

Algeria is classified among the poorest countries as regards hydrous potentialities, in lower part of the theoretical threshold of scarcity fixed by the World Bank at $1000 \mathrm{~m}^{3}$ hab year. It is in this context that the recourse to the wastewater reuse is essential and becomes an obvious reality, permits on the one hand to protect the environment, in order to avoid the surface contamination and underground fresh waters and on the other hand, to bring additional water quantities not requiring a drinkable quality to reuse them in agriculture and industry, two sectors large-scale consumer water. Adsorption permits removal of organic colloids which play an important role in fouling phenomena. Kim et al. ${ }^{[1]}$ showed that the coupling of mineral clay ultrafiltration allowed a membrane fouling reduction. The advantage of such a hybrid method is the fast and effective adsorption of the organic matter by the adsorbents. Brasquet et $a l^{[2]}$ proceeded to the coupling adsorption ultrafiltration while using like adsorbing agent of the fibrous activated carbon and a Tech Sep membrane with cut off $3000 \mathrm{Kg} \mathrm{moL}^{-1}$. The coupling allowed the elimination of composed high molecular weight and low-weight molecular. Adsorption isotherms were realised on synthetic solutions containing phenol concentration equal to $125 \mathrm{mg} \mathrm{L}^{-1}$. The maximum capacities adsorption are respectively $\mathrm{C}^{*}=117 \mathrm{mg} \mathrm{g}^{-1}$ for the granular activated carbon and $143 \mathrm{mg} \mathrm{g}^{-1}$ for the fibrous activated carbon. Lin et $a l .^{[3]}$ showed that the use of the powder activated carbon like the pre-treatment with ultrafiltration or combination, allowed the fouling membrane reduction. The powder activated carbon is ineffective for solutes of molecular weights less than $300 \mathrm{Kg} \mathrm{mo} \mathrm{L}^{-1}$ and more than $17000 \mathrm{Kg} \mathrm{mol}^{-1}$. In our previous study ${ }^{[4]}$ the addition of ferric chloride as coagulant and powder activated carbon as adsorbent in the feed ( secondary effluent) of an UF equipment improves the permeate flux and the quality of the permeate. Seo et al. ${ }^{[5]}$

Corresponding Author: D. Abdessemed, Laboratory of Processes Engineering Environment,

University of Sciences and Technologies, Houari Boumediene, Bab Ezzouar, Algiers, Algeria

Tel: +21371851243 Fax: +21321247919 
Am. J. Environ. Sci., 4 (6): 716-720, 2008

Table 1: Characteristics of secondary water of Staoueli

\begin{tabular}{lc}
\hline Parameter & Mean value \\
\hline Temperature $\left({ }^{\circ} \mathrm{C}\right)$ & 23.50 \\
pH & 7.80 \\
Turbidity $(\mathrm{NTU})$ & 16.00 \\
Conductivity $\left(\mu \mathrm{S} \mathrm{CM}^{-1}\right)$ & 1474.00 \\
$\mathrm{BOD}_{5}\left(\mathrm{mg} \mathrm{O}_{2} \mathrm{~L}^{-1}\right)$ & 13.83 \\
$\mathrm{COD}\left(\mathrm{mg} \mathrm{O}_{2} \mathrm{~L}^{-1}\right)$ & 76.00 \\
$\mathrm{SS}\left(\mathrm{m} \mathrm{L} \mathrm{L}^{-1}\right)$ & 22.16 \\
\hline
\end{tabular}

proceeded to the coupling of the Biological Powdered Activated Carbon (BPAC) with microfiltration with the aim of producing treated water able to be reused. The average removal efficiency of the organic matter was $83 \%$, for an initial COT concentration of the effluent of $9.8 \mathrm{mg} \mathrm{L}^{-1}$. In reference to these research, the present study is related to elimination of the chemical oxygen demand still present at the level of the secondary effluents. For that, we directed our study towards the determination of the optimum conditions for the adsorption coupled with ultrafiltration.

Experimental conditions: The experimental study was carried a secondary effluent settling at the wastewater treatment plant of Staoueli (Algeria) functioning by a system with activated sludge.

Characteristics of the secondary effluent: The secondary effluent of the wastewater treatment plant of Staoueli (Algeria) has the following average characteristics (period January-September 2005) are shown in the Table 1.

Procedures: Initially, we considered the adsorption of the organic matter on bentonite in static mode (jar-test) at ambient temperature. In the second time, variable bentonite amounts $\left(0-20 \mathrm{~g} \mathrm{~L}^{-1}\right)$ are added directly in the feed tank to the secondary effluent for its ultrafiltration.

Experimental set up: This consists of feed tank (1) where the adsorbents is added, a heat exchanger (2), a centrifugal pump (3), a flow meter (4), control valves (5), manometers(6), a mineral membrane ultrafiltration tubular (7) CARBOSEP M2 (15 $\left.\mathrm{Kg} \mathrm{mo}^{-1}\right)$ in dynamic mode with a transmembrane pressure ? $\mathrm{P}=1$ bar and a cross flow velocity $\mathrm{U}=3 \mathrm{~m} \mathrm{sec}^{-1}$ (Fig. 1).

Reagents: The bentonite (bleaching ground) is an inexpensive local mineral. The bentonite contains more than montmorillonite $75 \%$ and constitutes the principal part most active. The average exchange capacity of montmorillonite varies from $8-15 \mathrm{meq} / 100 \mathrm{~g}$ clay. The physical characteristics of bentonite used are given in Table 2.
Table 2: Characteristics physics of Maghnia bentonite

\begin{tabular}{ll}
\hline Characteristics & Description \\
\hline Humidity & $10 \%$ max \\
Density & $0.5 \mathrm{~g} \mathrm{~cm}^{-3}$ \\
pH & $3-4$ \\
Bleaching capacity & $95-98 \%$ \\
\hline
\end{tabular}

Table 3: Average chemical composition of Maghnia bentonite

\begin{tabular}{ll}
\hline Elements & Composition (\%) \\
\hline $\mathrm{SiO}_{2}$ & $60-70$ \\
$\mathrm{Al}_{2} \mathrm{O}_{3}$ & $17-20$ \\
$\mathrm{Fe}_{2} \mathrm{O}_{3}$ & $3-\mathrm{Jan}$ \\
$\mathrm{CaO}$ & $0.5-1$ \\
$\mathrm{Mg} \mathrm{O}$ & $2.5-4$ \\
$\mathrm{Na}_{2} \mathrm{O}$ & $2-\mathrm{Jan}$ \\
$\mathrm{K}_{2} \mathrm{O}$ & $0-0.74$ \\
\hline
\end{tabular}

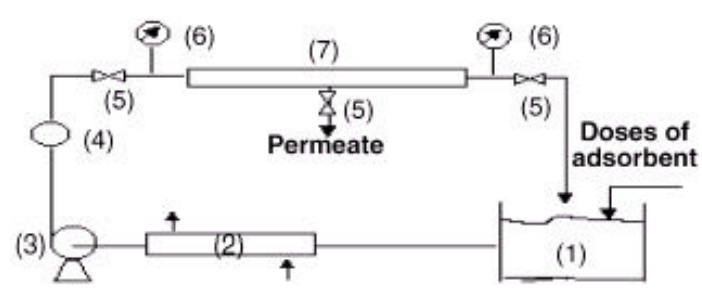

Fig. 1: Experimental set-up

And the Table 3 hereafter illustrates the chemical composition of bentonite.

\section{RESULTS AND DISCUSSION}

Determination of the adsorption optimal conditions: The given optimal conditions correspond to the best elimination of the Chemical oxygen Demand with a final value equal to $30.6 \mathrm{mg} \mathrm{L}^{-1}$ as shown in the Fig. $2 \mathrm{a}$ and a turbidity in jar test with a value of 1.5 NTU for one optimal bentonite concentration equal to $10 \mathrm{~g} \mathrm{~L}^{-1}$ (Fig. 2b).

Adsorption kinetic: We followed the concentration in COD evolution according to time after addition of an optimal bentonite concentration (Fig. 3) on a sample of secondary effluent.

The kinetic study made it possible to note that the time necessary to obtain the adsorption equilibrium is $6 \mathrm{~h}$ with the removal efficiency COD is $63 \%$, a residual value of $28 \mathrm{mg} \mathrm{L}^{-1}$.

Adsorption isotherm: The adsorption isotherms were established by observing after a contact time of $6 \mathrm{~h}$. The results obtained reveal a linear variation between the quantity of the organic matter adsorbed and its equilibrium concentration, in solution $\mathrm{C}_{\mathrm{e}}\left(\mathrm{mg} \mathrm{\textrm {L } ^ { - 1 }}\right)$ according to Fig. 4. 


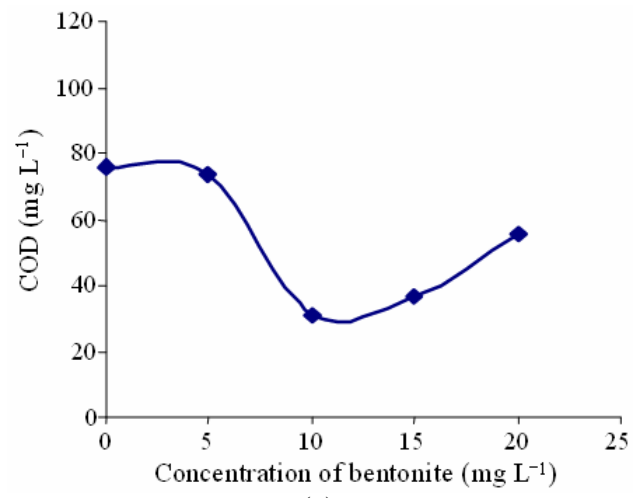

(a)

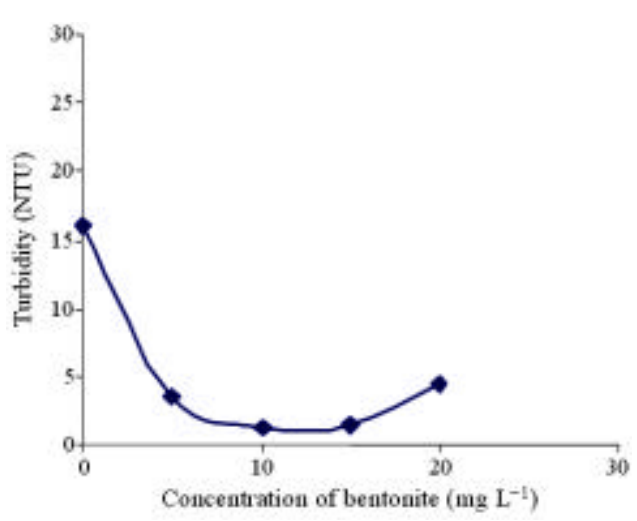

(b)

Fig. 2: Variation of the COD (a) and the turbidity (b) according to the bentonite concentration

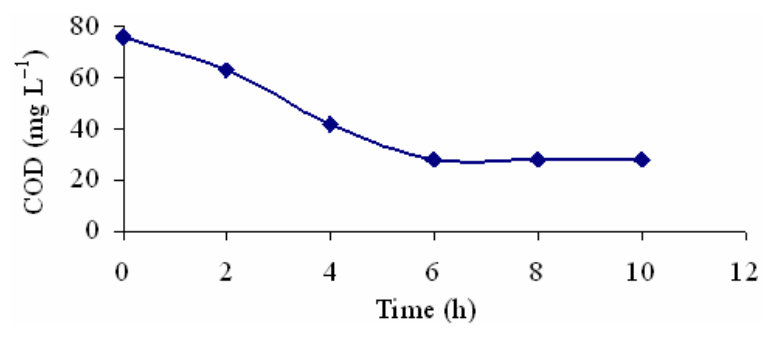

Fig. 3: Adsorption kinetic for $\mathrm{C}=10 \mathrm{~g} \mathrm{~L}^{-1}$

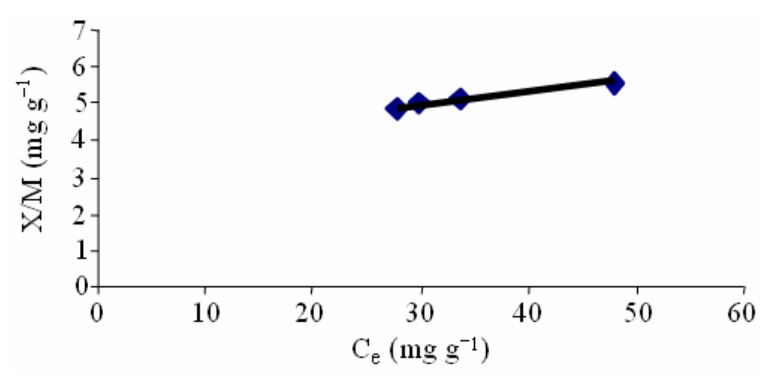

Fig. 4: Adsorption isotherm at $\mathrm{t}=6 \mathrm{~h}$
These isotherms were modelled by the Freundlich and Langmuir equations, which give the equilibrium adsorption capacity $\mathrm{X} / \mathrm{M}\left(\mathrm{mg} \mathrm{g}^{-1}\right)$ according to the equilibrium concentration in solution $\mathrm{C}_{\mathrm{e}}\left(\mathrm{mg} \mathrm{L}^{-1}\right)$ according to respectively:

$\mathrm{X} / \mathrm{M}=\mathrm{kC}_{\mathrm{e}}{ }^{1 / \mathrm{n}}$

and

$\frac{X}{M}=\frac{b C^{*} C_{e}}{1+b C_{e}}$

$\mathrm{X} / \mathrm{M}=$ Quantity adsorbed per unit of added bentonite mass

$\mathrm{C}_{\mathrm{e}}=$ Chemical oxygen demand at the equilibrium,

$\mathrm{k}, 1 / \mathrm{n}=$ Freundlich constants

$\mathrm{b}=$ Langmuir's equilibrium parameter

$\mathrm{C}^{*}=$ Maximum adsorption capacity

Freundlich model: The representation graphic (Ln $\mathrm{X} / \mathrm{M}$ ) according to ( $\mathrm{Ln} \mathrm{C}_{\mathrm{e}}$ ) gives access to us the constants $\mathrm{k}$ and $\mathrm{n}$, with $\mathrm{n}=3.855, \mathrm{k}=2.049$, $\mathrm{X} / \mathrm{M}=2.049 \mathrm{C}_{\mathrm{e}}^{0.26}$

Langmuir model: With the graph $M / X=f\left(1 / C_{e}\right)$, we obtain an average straight lines as the Fig. 5 b shows it. The maximum adsorption capacity, is given by the

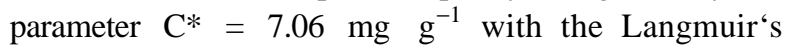
equilibrium parameter $\mathrm{b}=0.031 \mathrm{Lg}^{-1}$

$\mathrm{X} / \mathrm{M}$ and the function expression is written as follows:

$\frac{\mathrm{X}}{\mathrm{M}}=\frac{0.07 \cdot 7 \cdot 06 \mathrm{C}_{\mathrm{e}}}{1+0.07 \mathrm{C}_{\mathrm{e}}}$

The isotherm obtained to $293 \mathrm{~K}$ relates in conformity with that of type I, of Langmuir to an adsorption according to a monomolecular layer.

Evolution of the permeate flux according to time: The permeate flux decreases with the time, that is due to the progressive accumulation of the species stopped on the surface and the pores of the membrane thus inducing phenomena of concentration polarization and fouling partial of the pores. The addition of the various bentonite amounts is an advantageous contribution, because the limit permeate flux value passes from a $30.5 \mathrm{~L} \mathrm{~h}^{-1} \mathrm{~m}^{2}$ (without addition) to a maximum value of $45.3 \mathrm{~L} \mathrm{~h}^{-1} \mathrm{~m}^{2}$ for a bentonite concentration of $10 \mathrm{~g} \mathrm{~L}^{-1}$, an increase of $48.8 \%$. This results in a competition between the two techniques (ultrafiltration and 


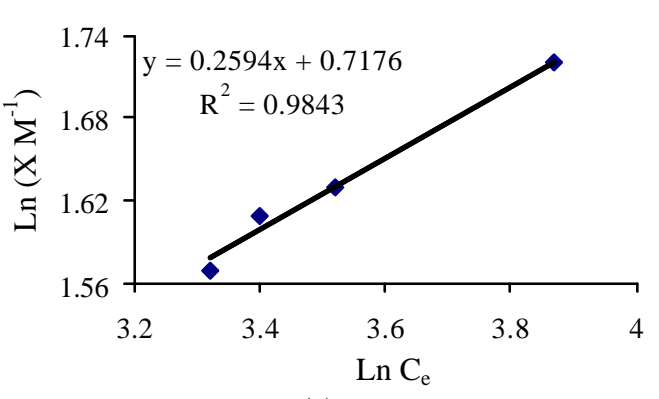

(a)

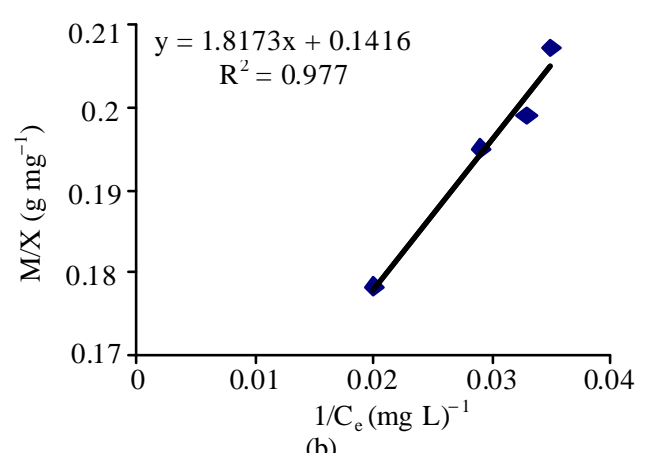

Fig. 5: Representations graphic according to the Freundlich model (5a) according to the Langmuir model (5b)

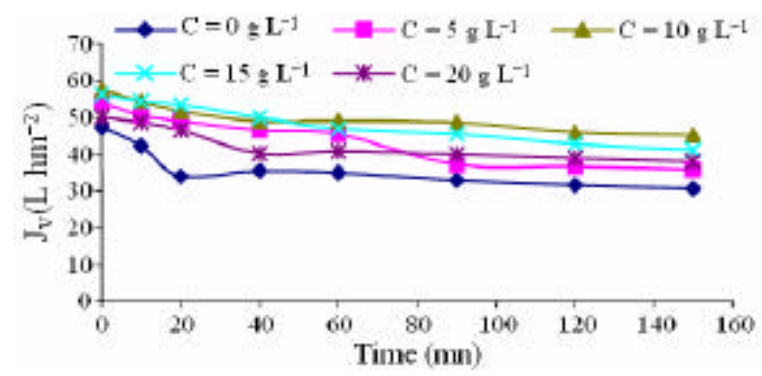

Fig. 6: Variation of permeate flux according to the time for the bentonite for various concentrations

adsorption) for the molecular species elimination. This shows that the bentonite allowed a good adsorption of the molecules which are at the origin of the ultrafiltration membranes fouling (Fig. 6).

COD reduction: Figure 7 shows a significant reduction of the COD is $88 \%$ compared to the initial value for the membrane M2. There is thus a very good complementarity's between bentonite able to retain certain molecules and the ultrafiltration membrane able to retain the large molecules and colloids. The bentonite addition contributes $\mathbf{b}$ the COD elimination with the optimal bentonite $\mathrm{C}$ concentration $=10 \mathrm{~g} \mathrm{~L}^{-1}$. The residual COD value is $9 \mathrm{mg} \mathrm{L}^{-1}$.

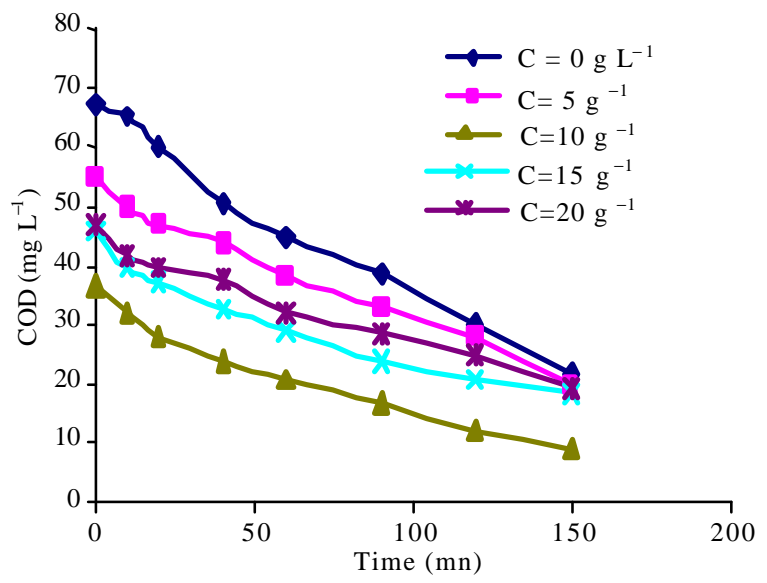

Fig. 7: Variation of the COD according to the time for the various concentrations

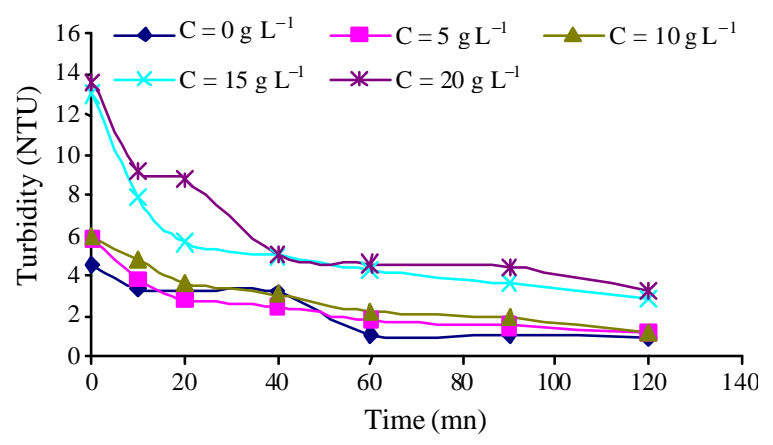

Fig. 8: Variation of the turbidity according to the time for various adsorbent concentrations

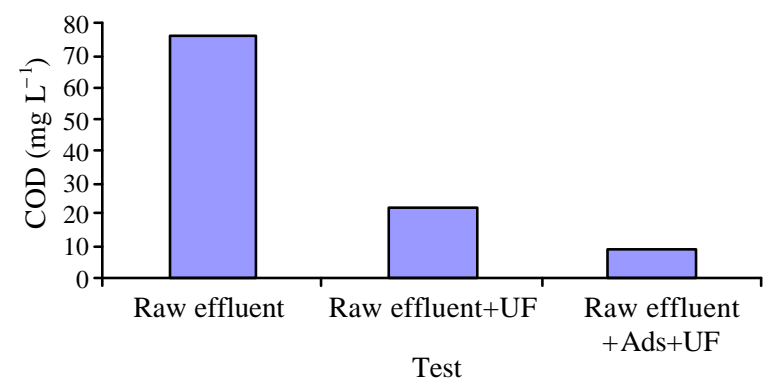

Fig. 9: Variation of the COD according to the various tests

Turbidity reduction: According to Fig. 8, turbidity decreases according to time for the various bentonite concentrations, however, the lowest value is obtained for the test without adsorbent, a rate of elimination of $94.8 \%$.

Variation of the Chemical oxygen demand for different process: Figure 9 compares the quality water obtained for the various processes tested. The best 
result is obtained coupling adsorption ultrafiltration with final of COD equal to $9 \mathrm{mg} \mathrm{L}^{-1}$.

The residual limiting values showed that the coupling of the two techniques (adsorption-UF) increases the elimination efficiency of the two parameters.

\section{CONCLUSION}

We could show the feasibility of the coupling adsorption-ultrafiltration. The results obtained show a significant reduction in the chemical oxygen demand for the ultrafiltration membrane M2 (cut off $15000 \mathrm{Kg} \mathrm{moL}{ }^{-1}$ ). An improvement of the permeate flux $48.8 \%$ is obtained. Adsorption improves in a significant way the ultrafiltration performances. The use of bentonite made it possible to retain certain molecules of low molecular mass, that ultrafiltration alone does not make it possible to stop (micropollutants). The COD decreases from $76-22 \mathrm{mg} \mathrm{L}^{-1}$ in the case of only one ultrafiltration and up to $9 \mathrm{mg} \mathrm{L}^{-1}$ in the bentonite presence for an optimal concentration of $10 \mathrm{~g} \mathrm{~L} \mathrm{~L}^{-1}$ for the same membrane M2: the permeate obtained can on the one hand be reused and on the other hand, the me mbrane pores internal fouling is reduced.

\section{REFERENCES}

1. Kim, C., M. Hosomi, A. Murakami and M. Okada, 1994. Effect of clay on the fouling by organic substances in portable treatment by ultrafiltration. Water Sci. Technol., 30: 159-167.

2. Brasquet, C., E. Subrenat and P. Lecloirec, 1997. Selective adsorption on fibrous activated carbon of organics from aqueous solution: Correlation between adsorption and molecular structure. Water Sci. Technol., 35: 251-259. http://cat.inist.fr/ ?aModele $=$ afficheN\&cpsidt $=2730934$.

3. Lin, C.F., Y. Huang and O.J. Hao, 1999. Ultrafiltration processes from removing humic substances: Effect of molecular weight fractions and PAC treatment. Water Res., 33: 1252-1264. http:// cat.inist.fr/?aModele $=$ afficheN\&cpsidt $=1704542$.

4. Abdessemed, D., G. Nezzal and R. Ben Aim, 2003. Coagulation adsorption ultrafiltration for wastewater treatment and reuse. Water Supply, 3: 361-365. http://cat.inist.fr/ ?aModele $=$ afficheN\&cpsidt $=16143816$.

5. Seo, G.T., Y. Suzuki and S. Ohgaki, 1996. Biological Powdered Activated Carbon (BPAC) microfiltration for wastewater reclamation and reuse. Desalination, 106: 39-45. http:// cat.inist.fr/?aModele $=$ afficheN\&cpsidt $=3213791$. 